\title{
High-intensity exercise and recovery during short-term supplementation with creatine plus a protein-carbohydrate formula
}

\author{
J R Clark (BSc (Hons)(Human Physiology), BA (HMS)(Hons)(Biokinetics), CSCS (NSCA)) \\ Department of Biokinetics, Sport and Leisure Sciences, Institute for Sport Research, University of Pretoria
}

\begin{abstract}
Objective. To determine the effect of short-term creatine supplementation plus a protein-carbohydrate formula on high-intensity exercise performance and recovery.

Design. A repeated-measures, experimental study, employing a randomised, double-blind, placebo-controlled, group comparison design was used.

Interventions. Thirty active but not sprint-trained male subjects were randomly assigned to 1 of 3 groups: creatine plus protein-carbohydrate formula (CRF); creatine only (CRE); and control (CON). All groups were exposed to the same high-intensity sprint exercise programme, 3 times per week for 30 days.
\end{abstract}

Main outcome measures. Dependant variables included total repeat sprint distance, fatigue index, perceived muscle pain, and blood lactate, urea, creatine kinase, and cortisol concentrations.

Results. All groups significantly $(p \leq 0.05)$ increased total sprint distance and decreased blood urea concentrations. There were no significant changes in blood lactate or cortisol concentrations in any group. CRF showed significant decreases $(p \leq 0.05)$ in fatigue index, muscle pain, and creatine kinase concentration. However, no significant differences were found between groups.

Conclusion. Short-term creatine supplementation with or without protein-carbohydrate supplementation does not appear to enhance performance or recovery significantly over high-intensity exercise training alone in non-sprinttrained individuals. A longer trial period may be required to evaluate effect on recovery more conclusively. In addition, the prime importance of physical conditioning, and in particular task-specific exercise training, in stimulating performance and recovery adaptations is highlighted.

\section{CORRESPONDENCE:}

\section{J R Clark}

Institute for Sport Research

LC de Villiers Sport Centre

University of Pretoria

Tel: 012-420 6033

Fax: 012-420 6099

E-mail: jimmy.clark@up.ac.za

\section{Introduction}

Following its sweeping rise in popularity in the lay press and extensive scientific publications in the last decade, creatine remains one of the most widely used and recommended nutritional supplements for the purpose of obtaining an ergogenic effect. ${ }^{1,4,14-18,27,36}$ It is frequently recommended to power athletes and other individuals wishing to improve performance in high-intensity training or competition, or seeking gains in strength and muscle mass. 1,2,4,5,9,14,21,22,36

Creatine is an amino acid derivative which is both synthesised in the body and obtained in the diet, mainly from meat sources. ${ }^{1,36}$ Most is stored within skeletal muscle fibres, where it is found in its free $(\mathrm{Cr})$ and phosphorylated (phosphocreatine (PC)) form. The biological significance of $\mathrm{PC}$ lies in its ability to assist in rapidly resynthesising adenosine triphosphate (ATP) during high-intensity work via the cytosolic creatine kinase reaction, thereby buffering an immediate decrease in ATP concentration. ${ }^{4,9,21,36}$ Only limited amounts of PC ( 70 - 90 mmol. $\mathrm{kg}^{-1}$ dry muscle) are stored, and maximal intensity exercise rapidly depletes it, slowing PC contribution to ATP resynthesis and concomitantly augmenting the stimulation of other bio-energetic pathways. $^{2,4,9,21}$ Creatine also has other important physiological functions, including buffering free intracellular protons and coupling mitochondrial oxidative resynthesis of ATP to its cytosolic hydrolysis - the so-called creatine phosphate shuttle. ${ }^{1,2,4,36}$

A sizable amount of research has been conducted on the effect of creatine supplementation on physical performance. It has been reported that there are benefits to enhancing the skeletal muscle store of creatine. These include improved maintenance of maximal power outputs, ${ }^{1,2,4,5,17,18,31}$ more rapid recovery from high-intensity exercise, ${ }^{14,15,27,35,36}$ and diminished post-exercise muscular pain. ${ }^{35,36}$ Creatine supplementation in combination with high-intensity exercise training has been shown to improve short-term power output, and is reportedly most beneficial for maximising repeated high-intensity work performance. ${ }^{1,2,5,16,31,36}$ Such activities as resistance training, ${ }^{35}$ and all-out intensity cycling, ${ }^{8}$ sprinting, ${ }^{11}$ jumping, ${ }^{36}$ swimming ${ }^{10}$ and rowing ${ }^{29}$ are sited as benefiting, while some researchers have reported benefits in clinical rehabilitation. ${ }^{1,18}$

Even short-term creatine supplementation (4 - 6 weeks) has been associated with improved power output in single 
and repetitive maximal exercise tasks lasting less than 30 seconds. ${ }^{1,2,4,36}$ In repeated bouts of high-intensity exercise, creatine supplementation attenuated fatigue ${ }^{17}$ and resulted in better sustained power output over the duration of an exercise set. ${ }^{1,36}$ Since ATP and PC stores are limited, it seems reasonable to hypothesise that increasing the concentration of free creatine and PC within skeletal muscle may improve performance in maximal work demanding these substrates for rapid ATP resynthesis. Greater levels of intracellular creatine may also result in improved PC resynthesis during the recovery period, maximising power output in subsequent efforts. ${ }^{1,36}$ It has also been hypothesised to act as a buffer to muscle cell acidity during high intensity work. ${ }^{2}$

For athletes, a notable reported benefit of creatine supplementation is enhanced recovery from high-intensity work. 1,14,21,27,36 Carbohydrate replenishment following exercise is widely recommended as a means to enhance the recovery process. ${ }^{2,4,5,21}$ Combined carbohydrate and protein supplementation has been shown to enhance recovery following endurance exercise, with more rapid replenishment of muscle glycogen, ${ }^{12}$ reduced muscle soreness, ${ }^{23}$ and improved performance in subsequent bouts of exercise. ${ }^{25}$ More specifically, addition of protein seems less beneficial when sufficient carbohydrate is ingested, ${ }^{3,13}$ although addition of even small amounts of essential amino acids to carbohydrate may enhance recovery. ${ }^{6}$ It is unclear whether combined protein-carbohydrate supplementation enhances recovery from high-intensity sprint exercise, although the coingestion of carbohydrate and amino acids has been shown to stimulate net muscle protein synthesis following resistance exercise. ${ }^{24}$ Combining creatine supplementation with protein and carbohydrate supplementation is sometimes promoted by dietary supplement manufacturers as maximising work performance while improving recovery following exercise training. This supplementation strategy is claimed to enhance the training effect. However, scientific investigations are required to validate such claims. Therefore, the purpose of this pilot trial was to investigate the effect of creatine supplementation versus creatine combined with a proteincarbohydrate formula on high-intensity exercise performance and recovery.

\section{Methods}

\section{Subjects}

Thirty male subjects volunteered for the study. All were healthy physical education students with the following characteristics (mean \pm standard deviation (SD)): age $20.0 \pm$ 2.0 years, stature $179.4 \pm 6.4 \mathrm{~cm}$, body mass $77.4 \pm 14.3 \mathrm{~kg}$, body mass index (BMI) $23.9 \pm 3.5 \mathrm{~kg} \cdot \mathrm{m}^{-2}$, sum of 7 skinfolds $91.8 \pm 53.2 \mathrm{~mm}$. All were moderately active, reporting physical exercise 2 - 3 days per week. None of the subjects had any recent history of orthopaedic injury, hepatic or renal impairments. In addition, none of the subjects reported use of any nutritional supplement containing creatine, carbohydrate or protein, or any other supplement, within the 3 months prior to the study. The research protocol was approved by the
Research Proposal and Ethics Committee of the University of Pretoria. Prior to participation subjects were thoroughly briefed regarding the benefits and risks associated with the study, whereafter written informed consent was obtained.

\section{Procedures}

All data collection was carried out at the Institute for Sport Research, University of Pretoria. An experimental study was undertaken, employing a randomised, double-blind, placebocontrolled, group comparison design. ${ }^{33}$ Subjects were randomly assigned to 1 of 3 groups: creatine plus a proteincarbohydrate formula (CRF, $N=10$ ); creatine only (CRE, $N$ = 10); and control (CON, $N=10)$. All subjects underwent testing before and after 30 days of supplementation and repeat sprint exercise training. The pre-test and post-test sessions were each conducted over 2 consecutive days. On day 1 , subjects completed a high-intensity sprint running performance test. Day 2 involved blood sampling and evaluation of perceived muscle pain. Running performance measures involved analysis of repeat sprint performance, while recovery measures assessed perceived muscle pain and blood markers of muscle damage the day after highintensity running exercise. A time line for events in the study is outlined in Fig. 1.

\section{Physical testing}

Preliminary testing of subjects involved body mass, stature, and skinfold measurement (Harpenden Caliper, Baty International, British Indicators) which were used to calculate BMI and sum of 7 skinfolds. ${ }^{26}$ Thereafter, subjects engaged in a standardised 10-minute warm-up consisting of selfpaced easy running, static stretching and dynamic drills. Subjects then performed a maximal-effort, repeated sprint running test, involving $10 \times 10$-second maximal sprints, with $90 \mathrm{~s}$ walk recovery between each sprint. This protocol is similar in intensity, volume, and work-rest ratio to others used to assess efficacy of creatine supplementation in a large number of reported studies. ${ }^{36}$ Subjects sprinted on a level, even, grass surface, in a straight line, with markers along the length of the run. Strong verbal encouragement was given throughout to motivate maximum performance. The distance run in each $10 \mathrm{~s}$ sprint was recorded to the nearest metre, and the sum of the total sprint distance in the $100 \mathrm{~s}$ was calculated. Also, the individual sprint distances were used to calculate a sprint fatigue index (\%) as follows: Fatigue index $=(\max -\min ) / \max x 100$, where $\max$ is the greatest distance $(\mathrm{m})$, and $\mathrm{min}$ is the shortest distance $(\mathrm{m})$ achieved in any single $10 \mathrm{~s}$ sprint. Blood lactate concentration ([La $\left.]_{B}\right)$ was measured directly following completion of the test using a Lactate Pro (Arkray, Inc. Shiga, Japan) portable blood lactate meter, using finger capillary blood obtained using standard methods as described by Maw et al. ${ }^{20}$ All physical testing was performed at the same time of day on each test occasion. Subjects were instructed to arrive well rested for the test days, and to avoid physical exercise on the day prior to, and after, physical testing. 
Days

\begin{tabular}{|c|c|c|c|c|c|c|c|c|c|c|c|c|c|c|c|c|c|c|c|c|c|c|c|c|c|c|c|c|c|}
\hline 1 & 2 & 3 & 4 & 5 & 6 & 7 & 8 & 9 & 10 & 11 & 12 & 13 & 14 & \begin{tabular}{|l|}
15 \\
\end{tabular} & 16 & 17 & 18 & 19 & 20 & 21 & 22 & 23 & 24 & 25 & 26 & 27 & 28 & 29 & 30 \\
\hline 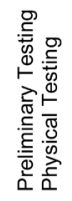 & 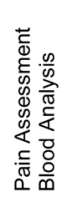 & 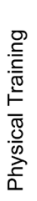 & & 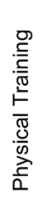 & & & 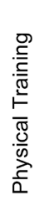 & & 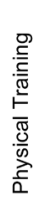 & & 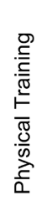 & & & 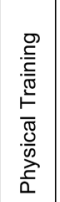 & & 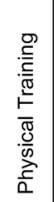 & & 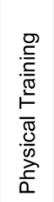 & & & 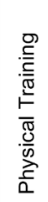 & & 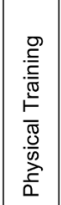 & & 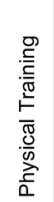 & & & 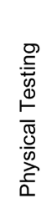 & 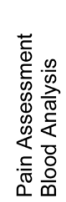 \\
\hline & & & & & & & & & & & & & Per & od of $\mathrm{c}$ & $\frac{1}{\text { daily su }}$ & sur & ementa & ation & & & & & & & & & & & \\
\hline
\end{tabular}

Fig. 1. Time line of events.

\section{Pain assessment and blood analysis}

The morning after the day of physical testing subjects reported for pain score assessment and blood sampling. This took place at the same time of day on each occasion, and subjects arrived fasted. Perceived local leg muscle pain was evaluated by means of a visual analogue scale (VAS). VASs have been validated for assessment of pain ${ }^{28}$ and their use is widespread. ${ }^{7,19}$ Subjects were asked to report their perceived muscle soreness experienced during activities of daily living (ADL) following sprint testing. Scores were obtained for perceived leg muscle pain in the last 24 hours prior to the pain assessment $\left(\mathrm{VAS}_{24 \mathrm{~h}}\right)$ and for pain at that moment of assessment $\left(V S_{\text {NOW }}\right.$ ). Blood samples were obtained and analysed for blood urea ([UREA $\left.]_{B}\right)$, creatine kinase $\left([C K]_{B}\right)$ and cortisol ([CORTISOL $\left.]_{\mathrm{B}}\right)$ concentrations.

\section{Exercise sessions}

All 3 groups were exposed to the same physical conditioning programme, consisting of high-intensity repeated sprint running exercise, exactly the same as that used in the physical testing i.e. $10 \times 10 \mathrm{~s}$ repeated maximal sprints with $90 \mathrm{~s}$ recovery between each sprint. These were conducted 3 days per week in supervised sessions to encourage maximal effort in training.

\section{Supplementation}

Supplementation commenced after the first set of blood samples were taken on day 2 of the study and continued for 29 days. CRF received creatine plus a commercially available protein-carbohydrate formula; CRE received creatine only; and CON received placebo. Creatine monohydrate was provided, with doses approximating $0.3 \mathrm{~g} . \mathrm{kg}^{-1}$ body mass for the first 7 days, and $0.03 \mathrm{~g} . \mathrm{kg}^{-1}$ thereafter, as widely reported to maximise skeletal muscle stores. ${ }^{1,5,36}$ In addition to the creatine, CRF received a $\sim 30 \mathrm{~g}$ serving of a protein-carbohydrate blend (whey protein, calcium caseinate, maltodextrin) twice daily, as recommended by the manufacturers, which approximated $110 \mathrm{kcal}$ per serving, and comprised $60 \%$ protein, $20 \%$ carbohydrate by volume. All subjects received instructions on individual dosage, as well as a supplementation log book to mark adherence to the supplementation and to record side-effects. Subjects were instructed to take the first serving in the morning, and the second serving within 30 minutes of completion of their sprint training or in the afternoon on non-training days. Subjects were instructed to maintain their habitual diets.

\section{Data analysis}

Data analysis procedures included descriptive and inferential statistics. The latter involved Friedman's rank test for $k$ correlated samples for differences between tests within the same group and the Kruskal-Wallis one-way analysis of variance for differences between groups on the dependant variables at both intervals. ${ }^{33,34}$ All differences were reported on the $5 \%$ level of confidence (i.e. $p \leq 0.05$ ). Dependant variables included total repeat sprint distance, fatigue index, $[\mathrm{La}]_{\mathrm{B}}, \mathrm{VAS}_{24 \mathrm{H}}, \mathrm{VAS}_{\mathrm{NOW}},[\mathrm{UREA}]_{\mathrm{B}},[\mathrm{CK}]_{\mathrm{B}}$, and $[\mathrm{CORTISOL}]_{\mathrm{B}}$.

\section{Results}

Table I presents the mean variables for all groups. No statistically significant differences were found between the 3 groups with regard to all repeat sprint measures (total distance, fatigue index, or $\left.[\mathrm{La}]_{\mathrm{B}}\right)$. Across time, all 3 groups showed significant increases in their total sprint distances. Even though there was a decrease in fatigue index scores in all 3 groups, CRF was the only group to show a statistically significant decrease $(p \leq 0.05)$ from pre-test to post-test.

No significant differences were found between groups on all perceived leg muscle pain measures. CRF showed a significant decline in $\mathrm{VAS}_{24 \mathrm{~h}}$ from pre-test to post-test. The other groups showed the same trend but with no statistically significant differences. CRE showed a significant decrease

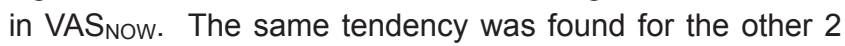
groups, but without statistical significance.

CRE had significantly lower scores than the other 2 groups on all measurements of [UREA $]_{B}$. No significant differences were found regarding $[\mathrm{CORTISOL}]_{B}$ or $[\mathrm{CK}]_{B}$ amongst the groups. Over time, there were significant decreases in [UREA $]_{B}$ scores in all 3 groups. No significant changes took place in [CORTISOL $]_{B}$. Only CRF had significant decreases in $[\mathrm{CK}]_{\mathrm{B}}$ scores from the pre-test to the post-test.

\section{Discussion}

Lack of statistically significant differences in repeat sprint measures between groups at the post-test is perhaps not surprising, since none of the subjects were sprint trained. Physiological adaptations to the sprint programme alone may 
TABLE I. Repeat sprint performance, perceived muscle pain, and blood concentration measures (mean \pm SD) before and after 30 days of supplementation and high-intensity sprint training

\begin{tabular}{|c|c|c|c|c|c|c|}
\hline & \multicolumn{2}{|c|}{ CRF } & \multicolumn{2}{|c|}{ CRE } & \multicolumn{2}{|c|}{ CON } \\
\hline & Pre-test & Post-test & Pre-test & Post-test & Pre-test & Post-test \\
\hline Total distance (m) & $612.5 \pm 51.4$ & $671.5 \pm 59.2$ * & $621.8 \pm 74.4$ & $712.0 \pm 32.5^{*}$ & $627.8 \pm 35.2$ & $698.1 \pm 29.2$ * \\
\hline Fatigue index (\%) & $21.2 \pm 5.8$ & $11.7 \pm 4.7^{*}$ & $21.2 \pm 10.2$ & $15.4 \pm 4.8$ & $23.4 \pm 13.1$ & $14.0 \pm 2.6$ \\
\hline Lactate $\left(\mathrm{mmol} . \mathrm{I}^{-1}\right)$ & $15.1 \pm 1.3$ & $13.3 \pm 1.8$ & $14.6 \pm 1.2$ & $15.4 \pm 4.8$ & $13.9 \pm 0.8$ & $13.2 \pm 2.4$ \\
\hline $\operatorname{VAS}_{24 h}(\mathrm{~mm})$ & $41.1 \pm 21.5$ & $12.4 \pm 9.3$ * & $34.2 \pm 25.4$ & $8.7 \pm 9.1$ & $47.0 \pm 25.8$ & $13.7 \pm 17.0$ \\
\hline VAS $_{\text {NOW }}(\mathrm{mm})$ & $22.3 \pm 17.1$ & $7.1 \pm 6.7$ & $38.2 \pm 29.2$ & $8.0 \pm 12.9$ * & $35.1 \pm 25.1$ & $9.5 \pm 10.2$ \\
\hline Urea (mg.dl ${ }^{-1}$ ) & $43.4 \pm 6.5$ & $31.8 \pm 5.9$ * & $38.3 \pm 4.7+$ & $23.8 \pm 3.6+^{*}$ & $50.0 \pm 15.4$ & $30.4 \pm 8.4$ * \\
\hline $\mathrm{CK}\left(U . \mathrm{I}^{-1} 37^{\circ} \mathrm{C}\right)$ & $1720 \pm 2268$ & $465 \pm 318$ * & $871 \pm 478$ & $799 \pm 763$ & $2002 \pm 2683$ & $1408 \pm 1567$ \\
\hline $\begin{array}{l}\text { Cortisol (nmol. }{ }^{-1} \text { ) } \\
{ }^{*} \text { Significantly differen } \\
+ \text { Significantly differen }\end{array}$ & $\begin{array}{l}525 \pm 135 \\
\text { from pre-test value } \\
\text { from other groups, }\end{array}$ & $\begin{array}{l}556 \pm 133 \\
05 \\
05\end{array}$ & $490 \pm 160$ & $577 \pm 176$ & $488 \pm 176$ & $553 \pm 215$ \\
\hline
\end{tabular}

explain the large improvement in all groups over the short trial period. These may include improved motor unit recruitment and synchronisation, but also increased intracellular PC and muscle glycogen concentration, and improved activity of the enzymes involved in their degradation and resynthesis. ${ }^{4,21}$ All groups showed a trend towards lower fatigue index scores. The same adaptations above could explain this reduced fatigue. Interestingly, only CRF showed a significantly lower fatigue index from pre-test to post-test.

No significant changes were found in $[\mathrm{La}]_{B}$ within any group over the period of the study. Higher blood lactate concentrations may have been expected given the observed improvement in power output (total distance in $100 \mathrm{~s}$ ). However, a variety of factors can influence blood lactate, and measures should be interpreted with caution. These include rate of change in exercise intensity, carbohydrate levels, exercise mode, monitoring precision, temperature, overtraining, and muscle damage. ${ }^{32}$ The lack of significant changes in $[\mathrm{La}]_{\mathrm{B}}$ despite an average $\sim 12 \%$ higher total sprint distance across all 3 groups may in itself be significant, with improved lactate oxidation a possible mechanism.

CRF and CRE showed statistically meaningful declines in $\mathrm{VAS}_{24 \mathrm{~h}}$ and $V A S_{\text {NOW, }}$, respectively. Once again though, changes were not sufficient to result in any significant differences between groups. It was theorised that supplementation with creatine and protein-carbohydrate may improve recovery by stimulating net protein synthesis while ensuring available precursors for structural repair and improved fibre integrity. While this may indeed contribute to reduced post-exercise muscle pain and discomfort, the physiological adaptations to sprint exercise discussed above may alone result in reduced exercise-induced tissue damage and perceived pain, through a variety of mechanisms, such as increasing the motor unit pool exposed to the work. ${ }^{2}$ Since even CON showed a trend towards far lower leg muscle pain or discomfort as measured by VAS, the latter explanation may be the more important.
Selected blood variables were measured that may reflect injury, recovery, or stress. Since all groups showed lower ( $p$ $\leq 0.05$ ) values for [UREA $]_{B}$ at the post-test, this may also be the result of training adaptations, specifically reduced postexercise protein degradation or increased protein synthesis. No differences between groups were observed that could point to a supplementation effect. Differences in levels of urea metabolism are likely due to individual differences in protein turnover. The significantly lower [UREA $]_{B}$ for $C R E$ at both tests may be due to the small sample size. The same can be said for the isolated differences found in $[\mathrm{CK}]_{B}$. No significant differences were found between groups or between tests for [CORTISOL] $]_{B}$, although this might not be surprising considering the complex nature of the hormone's response. $^{30}$

Intense muscular exercise results in skeletal muscle fibre damage..$^{2,4,21,30}$ Damage to the sarcolemma may result in the appearance of CK in the extracellular environment. ${ }^{2}$ Interestingly, a significant decrease was observed in $[\mathrm{CK}]_{B}$ values in $\mathrm{CRF}$, with a similar yet not significant trend appearing in CRE and CON. This may indicate reduced muscle damage from intense exercise following a period of training, a trend which, interestingly, parallels the observation in perceived muscle pain discussed above.

\section{Conclusions}

Elite sports performance requires intense training, often on a daily basis, and optimal recovery is vital for performance gains and maintaining training intensity. If the diet is inadequate to meet the athletes' requirements, correct nutritional supplementation use may have an important role to play. ${ }^{4,5,16,21}$ Whether this involves creatine with or without a protein-carbohydrate formula, optimal strategies need to be elucidated. Although prompting interesting speculation, the present results cannot serve as the basis for concluding a cause-and-effect relationship between short-term creatine 
plus protein-carbohydrate formula supplementation and improved high-intensity exercise performance or recovery. Factors which may have contributed to this and which have been proposed in other studies include a placebo effect, the relatively small magnitude of any treatment effect, and the unfamiliarity of the exercise task. ${ }^{1}$ It is suspected that a longer trial period with a larger, sprint-trained sample may more clearly highlight any possible differences. Future work should consider use of alternative study designs, athletic abilities, and other indicators of stress, tissue damage, and recovery. Certainly though, the importance of the training stimulus in adaptations is demonstrated, at least with regard to non-sprint-trained individuals. Athletes and coaches, and those starting training programmes would do well to keep this in mind when considering claims from dietary supplement manufacturers.

\section{Acknowledgements}

The author would like to thank the staff of the Institute for Sport Research, University of Pretoria, for their assistance in administration of the study.

\section{REFERENCES}

1. American College of Sports Medicine Roundtable. The physiological and health effects of oral creatine supplementation. Med Sci Sports Exerc 2000; 32: 706-17.

2. Åstrand PO, Rodahl K, Dahl HA, Stromme SB. Textbook of Work Physiology: Physiological Bases of Exercise. 4th ed. Champaign, III.: Human Kinetics, 2003.

3. Betts JA, Stevenson E, Williams C, Sheppard C, Grey E, Griffin J. Recovery of endurance running capacity: effect of carbohydrate-protein mixtures. International Journal of Sport Nutrition and Exercise Metabolism 2005; 15 : 590-609.

4. Brooks GA, Fahey TD, Baldwin KM. Exercise Physiology: Human Bioenergetics and its Applications. 4th ed. Boston: McGraw-Hill, 2005.

5. Burke LM. Sports supplements and sports foods. In: Hargreaves M, Hawley J, eds. Physiological Bases of Sports Performance. Sydney: McGraw-Hill, 2003.

6. Coleman E. When time is short, does the addition of protein to carbohydrate improve recovery? Sports Medicine Digest 2002; 24: 73, 75-6.

7. Collins SL, Moore RA, McQuay HJ. The visual analogue pain intensity scale: what is moderate pain in millimeters? Pain 1997; 72: 95-7.

8. Dawson B, Cutler M, Moody A, Lawrence S, Goodman C, Randall N. Effects of oral creatine loading on single and repeated maximal short sprints. Aust J Sci Med Sport 1995; 27: 56-61.

9. Foss ML, Keteyian SJ. Fox's Physiological Basis for Exercise and Sport. 6th ed. Boston: WCB McGraw-Hill, 1998

10. Grindstaff PD, Kreider RB, Bishop R. Effects of creatine supplementation on repetitive sprint performance and body composition in competitive swimmers. Int J Sport Nutr 1997; 7: 330-46.

11. Harris RC, Viru M, Greenhaff PL, Hultman E. The effect of oral creatine supplementation on running performance during maximal short-term exercise in man. J Physiol 1993; 467: 74.

12. Ivy JL, Goforth HW jun., Damon BM, McCauley TR, Parsons EC, Price TB. Early postexercise muscle glycogen recovery is enhanced with a carbohydrate-protein supplement. J Appl Physiol 2002; 93: 1337-44.

13. Jentjens RL, van Loon LJ, Mann CH, Wagenmakers AJ, Jeukendrup AE. Addition of protein and amino acids to carbohydrates does not enhance muscle glycogen synthesis. J Appl Physiol 2001; 91: 839-46.
14. Juhn MS. Oral creatine supplementation: separating fact from hype. The Physician and Sports Medicine 1999; 27: 47-57.

15. Kalman D. A closer look at creatine monohydrate. NSCA Performance Training Journal 2004; 3: 20-2.

16. Kohler R, Meltzer S, Jakoet I, Noakes T. A practical guide to the use of nutritional supplements in South Africa. South African Journal of Sports Medicine 2005; 17: 48-52.

17. Kreider RB, Ferreira M, Wilson M, et al. Effects of creatine supplementation on body composition, strength, and sprint performance. Med Sci Sports Exerc 1998; 30: 73-82.

18. Lambert CP, Archer RL, Carrithers JA, Fink WJ, Evans WJ, Trappe TA. Influence of creatine monohydrate ingestion on muscle metabolites and intense exercise capacity in individuals with multiple sclerosis. Arch Phys Med Rehabil 2003; 84: 1206-10.

19. Langley GB, Sheppeard H. The visual analogue scale: its use in pain measurement. Rheumatol Int 1985; 5: 145-8.

20. Maw G, Locke S, Cowley D, Witt P. Blood sampling and handling techniques. In: Gore CJ, ed. Physiological Tests for Elite Athletes. Lower Mitcham, Australia: Human Kinetics, 2000: 86-97.

21. McArdle WD, Katch FI, Katch VL. Exercise Physiology: Energy, Nutrition, and Human Performance. 5th ed. Philadelphia: Lippincott Williams and Wilkins, 2001.

22. McNaughton LR, Dalton B, Tarr J. The effects of creatine supplementation on high-intensity exercise performance in elite performers. Eur J Appl Physiol 1998; 78: 236-40.

23. Millard-Stafford ML, Warren GL, Thomas LM, Doyle JA, Snow TK, Hitchcock K. Recovery from run training: efficacy of a carbohydrate-protein beverage? International Journal of Sport Nutrition and Exercise Metabolism 2005; 15: 610-24.

24. Miller SL, Tipton KD, Chinkes DL, Wolf SE, Wolfe RR. Independent and combined effects of amino acids and glucose after resistance exercise. Med Sci Sports Exerc 2003; 35: 449-55.

25. Niles ES, Lachowetz T, Garfi J, et al. Carbohydrate-protein drink improves time to exhaustion after recovery from endurance exercise. Journal of Exercise Physiology Online 2001: 4(1): 45-52.

26. Norton K, Marfell-Jones M, Whittingham N, et al. Anthropometric assessment protocols. In: Gore CJ, ed. Physiological Tests for Elite Athletes. Lower Mitcham, Australia: Human Kinetics, 2000: 66-85.

27. Plisk SS, Kreider RB. Creatine controversy? Strength and Conditioning Journal 1999; 21: 14-23.

28. Price DD, McGrath PA, Rafii A, Buckingham B. The validation of visual analogue scales as ratio scale measurements for chronic and experimental pain. Pain 1983; 17: 45-56.

29. Rossiter HB, Cannell ER, Jakeman PM. The effect of oral creatine supplementation on the 1000-m performance of competitive rowers. J Sports Sci 1996; 14: 175-9.

30. Sherwood L. Human Physiology: From Cells to Systems. 5th ed. London: Brooks/Cole - Thomson Learning, 2004.

31. Smith JC, Stephens DP, Hall EL, Jackson AW, Earnest CP. Effect of oral creatine ingestion on parameters of the work rate-time relationship and time to exhaustion in high-intensity cycling. Eur J Appl Physiol 1998; 77 360-5.

32. Swart J, Jennings CL. Use of blood lactate concentration as a marker of training status. South African Journal of Sports Medicine 2004; 16: 3-7.

33. Tabachnick BG, Fidell LS. Using Multivariate Statistics. 3rd ed. Northridge: Harper Collins College Publishers, 1996.

34. Thomas JR, Nelson JK. Research Methods in Physical Activity. 3rd ed. Champaign, III.: Human Kinetics, 1996.

35. Volek JS, Ratamess NA, Rubin MR, et al. The effects of creatine supplementation on muscular performance and body composition responses to short-term resistance training overreaching. Eur J Appl Physiol 2004; 91: 628-637.

36. Williams MH, Kreider RB, Branch JD. Creatine: The Power Supplement. Champaign, III.: Human Kinetics, 1999. 